\title{
Subarachnoid hemorrhage after surgical treatment of unruptured intracranial aneurysms
}

\author{
Hidetoshi Matsukawa, MD, PhD, ${ }^{1}$ Hiroyasu Kamiyama, MD, ${ }^{1}$ Toshiyuki Tsuboi, MD, PhD, ${ }^{1}$ \\ Kosumo Noda, MD, ${ }^{1}$ Nakao Ota, MD, ${ }^{1}$ Shiro Miyata, MD, PhD, ${ }^{1}$ Takanori Miyazaki, MD, ${ }^{1}$ \\ Yu Kinoshita, MD, ${ }^{1}$ Norihiro Saito, MD, PhD, ${ }^{1}$ Osamu Takahashi, MD, MPH, PhD, ${ }^{2}$ \\ Rihee Takeda, MD, ${ }^{1}$ Sadahisa Tokuda, MD, ${ }^{1}$ and Rokuya Tanikawa, MD'

\begin{abstract}
${ }^{1}$ Department of Neurosurgery, Stroke Center, Teishinkai Hospital, Sapporo; and ${ }^{2}$ Center for Clinical Epidemiology, Internal Medicine, St. Luke's International Hospital, Tokyo, Japan
\end{abstract}

\begin{abstract}
OBJECTIVE Only a few previous studies have investigated subarachnoid hemorrhage (SAH) after surgical treatment in patients with unruptured intracranial aneurysms (UIAs). Given the improvement in long-term outcomes of embolization, more extensive data are needed concerning the true rupture rates after microsurgery in order to provide reliable information for treatment decisions. The purpose of this study was to investigate the incidence of and risk factors for postoperative SAH in patients with surgically treated UIAs.
\end{abstract}
METHODS Data from 702 consecutive patients harboring 852 surgically treated UIAs were evaluated. Surgical treat- ments included neck clipping (complete or incomplete), coating/wrapping, trapping, proximal occlusion, and bypass surgery. Clippable UIAs were defined as UIAs treated by complete neck clipping. The annual incidence of postoperative $\mathrm{SAH}$ and risk factors for SAH were studied using Kaplan-Meier survival analysis and Cox proportional hazards regres- sion models.

RESULTS The patients' median age was 64 years (interquartile range [IQR] 56-71 years). Of 852 UIAs, 767 were clippable and 85 were not. The mean duration of follow-up was 731 days (SD 380 days). During 1708 aneurysm years, there were 4 episodes of $\mathrm{SAH}$, giving an overall average annual incidence rate of $0.23 \%(95 \% \mathrm{Cl} 0.12 \%-0.59 \%)$ and an average annual incidence rate of $0.065 \%$ (95\% $\mathrm{Cl} 0.0017 \%-0.37 \%)$ for clippable UIAs (1 episode of SAH, 1552 aneurysmyears). Basilar artery location (adjusted hazard ratio [HR] 23, 95\% $\mathrm{Cl} 2.0-255, \mathrm{p}=0.0012$ ) and unclippable UIA status (adjusted HR 15, 95\% Cl 1.1-215, $p=0.046$ ) were significantly related to postoperative SAH. An excellent outcome (modified Rankin Scale score of 0 or 1) was achieved in 816 (95.7\%) of 852 cases overall and in 748 (98\%) of 767 clippable UIAs at 12 months.

CONCLUSIONS In this large case series, microsurgical treatment of UIAs was found to be safe and effective. Aneurysm location and unclippable morphologies were related to postoperative SAH in patients with surgically treated UIAs. https://thejns.org/doi/abs/10.3171/2017.3.JNS162984

KEY WORDS intracranial aneurysm; neurosurgical procedures; risk factors; subarachnoid hemorrhage; vascular disorders

$\mathrm{T}$

He prevalence of unruptured intracranial aneurysms (UIAs) has been estimated at 3.2\%, and in followup studies, the overall risk of subarachnoid hemorrhage (SAH) for patients with these lesions has been reported to be approximately $1 \%$ per year. ${ }^{35,42}$ Patients with UIAs are informed that they are at a risk of SAH, and this knowledge often creates anxiety for both patients and doctors, leading to a desire in both parties to attempt to control the risk of SAH with preventive treatments. Treatment decisions, however, should be based on comparisons between the results of preventive treatment and the natural course of UIAs, not on comparisons between the results of preventive treatment and outcome after SAH.

Although clip ligation is believed to be the most durable

ABBREVIATIONS IQR = interquartile range; $\mathrm{mRS}$ = modified Rankin Scale; $\mathrm{SAH}=$ subarachnoid hemorrhage; UIA = unruptured intracranial aneurysm. SUBMITTED November 29, 2016. ACCEPTED March 23, 2017.

INCLUDE WHEN CITING Published online October 27, 2017; DOI: 10.3171/2017.3.JNS162984. 
TABLE 1. Summary of $m R S$ scores in 852 surgical cases

\begin{tabular}{|c|c|c|c|c|c|c|c|}
\hline \multirow[b]{2}{*}{ Assessment } & \multicolumn{7}{|c|}{ mRS Score } \\
\hline & 0 & 1 & 2 & 3 & 4 & 5 & 6 \\
\hline \multicolumn{8}{|l|}{ Overall } \\
\hline Preop (n= 852) & $775(91)$ & $49(5.8)$ & $23(2.7)$ & $3(0.4)$ & $2(0.2)$ & & \\
\hline At discharge $(n=852)$ & $621(73)$ & $151(18)$ & $56(6.6)$ & $10(1.2)$ & $2(0.2)$ & $10(1.2)$ & $2(0.2)$ \\
\hline 6 mos postop $(n=852)$ & $749(88)$ & $50(5.9)$ & $33(3.9)$ & $8(0.9)$ & $2(0.2)$ & $8(0.9)$ & $2(0.2)$ \\
\hline 12 mos postop $(n=851)^{*}$ & $776(91)$ & $40(4.7)$ & $16(1.9)$ & $7(0.8)$ & $2(0.2)$ & $8(0.9)$ & $2(0.2)$ \\
\hline \multicolumn{8}{|l|}{ Clippable UIAs } \\
\hline Preop (n= 767) & $728(95)$ & $24(3.1)$ & $13(1.7)$ & $2(0.3)$ & & & \\
\hline At discharge $(n=767)$ & $585(76)$ & $128(17)$ & $46(6.0)$ & $7(0.9)$ & $1(0.1)$ & & \\
\hline 6 mos postop $(n=767)$ & $697(91)$ & $38(5.0)$ & $27(3.5)$ & $5(0.7)$ & & & \\
\hline 12 mos postop $(n=766)^{*}$ & $717(94)$ & $31(4.0)$ & $14(1.8)$ & $4(0.5)$ & & & \\
\hline
\end{tabular}

means of excluding an aneurysm from the circulation, ${ }^{22}$ some UIAs are not suitable for this treatment approach because of the surrounding vascular anatomy or dysplasia and branching or perforating arteries. ${ }^{5}$ In addition, published data suggest the risk of aneurysm recurrence, growth of the residual lesion, or SAH cannot be fully eliminated by endovascular or surgical treatment. ${ }^{7-9,16,34,37}$ Even in cases in which complete obliteration of the aneurysm is confirmed, patients may still be at risk for SAH. Therefore, SAH after initial treatment is an important issue in UIA management.

Reliable data on rupture rates of treated UIAs are needed in order to allow patients and health care providers to compare risks of endovascular and microsurgical treatment and arrive at the most appropriate decision on a case-by-case basis. To the best of our knowledge, only a few previous studies have investigated the rate of SAH after surgical treatment of UIAs. The aim of this study was to investigate the risk factors of postoperative SAH in patients with surgically treated UIAs.

\section{Methods}

This study is reported based on criteria from the STROBE (Strengthening the Reporting of Observational Study in Epidemiology) statement. ${ }^{43}$ The study protocol was approved by the ethics committee of Teishinkai Hospital. Patient consent was obtained in each case. Surgical indications for UIAs were described recently. ${ }^{25}$ We retrospectively reviewed 702 consecutive patients who were harboring 852 UIAs that were treated with direct surgery at our institutions between April 2012 and August 2015. Mycotic and traumatic UIAs were not included in this study.

We collected the following data: age, sex, smoking history (current vs former/never), history of SAH from other aneurysm, previous treatment of aneurysms, aneurysm location and side, type of surgical treatment, aneurysm size, whether UIAs were thrombosed, whether UIAs were symptomatic, multiple UIAs, whether UIAs needed bypass surgery, findings of postoperative diffusion-weight- ed imaging (DWI), and intra- and postoperative rupture. Clippable UIAs were defined as UIAs treated by clip ligation along the ideal closure line. As described by Ishikawa et al., the closure line is considered ideal if it "restores the original vascular configuration present before the aneurysm developed" and "the maximum of the pathological wall of the aneurysm is included within the clips."13 Aneurysm sizes were categorized as small $(<15 \mathrm{~mm})$, large (15-24 mm), and giant ( $\geq 25 \mathrm{~mm})$. The surgical technique of extracranial to intracranial high-flow bypass was described previously. ${ }^{26,27}$ The patients' clinical status was evaluated by means of the modified Rankin Scale (mRS) preoperatively, at discharge, and at 6- and 12-month follow-up examinations or the last hospital visit, ${ }^{40}$ either via telephone interviews with the patient or family members or during a physical examination in cases in which patients were able to visit our hospital. For patients without symptoms, a poor outcome was defined as an mRS score of 2-6. In patients with an mRS score greater than 1 due to UIA-related symptoms or other comorbidities, a poor outcome is defined as an increase in the mRS score of 1 or more points.

\section{Statistical Analysis}

Statistical analysis was performed using SPSS for Mac (version 21.0; IBM) and Stata software (StataCorp). Variables are expressed as mean (with standard deviation), median (with interquartile range [IQR]: 25th-75th percentile), or number of cases (\%), as appropriate. Fisher exact tests were performed for nominal variables. Pearson chi-square tests were used to assess associations between categorical variables, complemented by adjusted residual analysis. The normality of the data was evaluated using the Shapiro-Wilk test. Normally distributed continuous variables were compared using the Student t-test and non-normally distributed variables using the Mann-Whitney U-test.

Receiver operating characteristic curve analysis was performed for age and the binary endpoint of poor outcome and postoperative SAH, and the cutoff points for these variables that optimized sensitivity and specificity 
TABLE 2. Analysis of factors related to poor outcome at 12 months

\begin{tabular}{|c|c|c|c|c|}
\hline \multirow[b]{2}{*}{ Variable } & \multirow[b]{2}{*}{$\begin{array}{c}\text { Total } \\
(n=852)\end{array}$} & \multicolumn{2}{|c|}{ Outcome } & \multirow[b]{2}{*}{$p$ Value } \\
\hline & & $\begin{array}{c}\text { Poor } \\
(n=29)\end{array}$ & $\begin{array}{l}\text { Not Poor } \\
(n=823)\end{array}$ & \\
\hline \multicolumn{5}{|l|}{ Age } \\
\hline Median in yrs & 64 & 56 & 61 & \\
\hline IQR in yrs & $56-71$ & $22-57$ & $52-69$ & \\
\hline $\begin{array}{c}\text { No. of cases w/ pt } \\
\text { age } \geq 65 \mathrm{yrs}^{*}\end{array}$ & $420(49)$ & $21(72)$ & $399(49)$ & 0.011 \\
\hline Male sex* & $181(21)$ & $12(41)$ & $169(21)$ & 0.007 \\
\hline Current smoking & $271(32)$ & $10(35)$ & $261(32)$ & 0.75 \\
\hline History of SAH & $24(2.8)$ & $1(3.4)$ & $23(2.8)$ & 0.83 \\
\hline Laterality & & & & 0.81 \\
\hline Midline & $139(16)$ & $6(21)$ & $133(16)$ & \\
\hline Left side & $371(44)$ & $12(41)$ & $359(44)$ & \\
\hline Right side & $342(40)$ & $11(38)$ & $331(40)$ & \\
\hline Surgical treatment* & & & & $<0.0001$ \\
\hline Neck clipping & $768(90)$ & $13(45)$ & 755 (92) & \\
\hline Proximal clipping & $43(5.0)$ & $9(31)$ & $34(4.1)$ & \\
\hline Trapping & $31(3.6)$ & $5(18)$ & $26(3.2)$ & \\
\hline Partial clipping & $10(1.2)$ & $2(6.9)$ & $8(1.0)$ & \\
\hline Aneurysm size in $\mathrm{mm}$ & & & & $<0.0001$ \\
\hline Median & 4.7 & 19 & 4.6 & \\
\hline IQR & $3.4-6.7$ & $7.1-27$ & $3.4-6.5$ & \\
\hline Size & & & & $<0.0001$ \\
\hline Normal & $779(91)$ & $12(41)$ & 767 (93) & \\
\hline Large $^{*}$ & $45(5.3)$ & $8(28)$ & $37(4.5)$ & \\
\hline Giant* & $28(3.3)$ & $9(31)$ & $19(2.3)$ & \\
\hline Location* & & & & $<0.0001$ \\
\hline MCA & $216(25)$ & $2(6.9)$ & $214(26)$ & NS \\
\hline Paraclinoid ICA & $175(21)$ & $4(14)$ & $171(21)$ & NS \\
\hline ICA-PCoA & $136(16)$ & $4(14)$ & $132(16)$ & NS \\
\hline $\mathrm{ACoA}$ & $117(14)$ & $2(6.9)$ & $115(14)$ & NS \\
\hline Basilar top $\dagger$ & $60(7.0)$ & $11(38)$ & $49(6.0)$ & $<0.01$ \\
\hline AChA & $43(5.0)$ & 0 & $43(5.2)$ & NS \\
\hline VA & $39(4.6)$ & $3(10)$ & $36(4.4)$ & NS \\
\hline ACA & $28(3.3)$ & 0 & $28(3.4)$ & NS \\
\hline ICA top & $24(2.8)$ & 0 & $24(2.9)$ & NS \\
\hline PCA & $8(0.9)$ & 0 & $8(1.0)$ & NS \\
\hline Basilar trunk $†$ & $5(0.6)$ & $3(10)$ & $2(0.2)$ & $<0.01$ \\
\hline PICA & $1(0.1)$ & 0 & $1(0.1)$ & NS \\
\hline Thrombosed UIA* & $22(2.6)$ & $7(24)$ & $15(1.8)$ & $<0.0001$ \\
\hline Nonsaccular UIA* & $34(4.0)$ & $6(21)$ & $28(3.4)$ & $<0.0001$ \\
\hline Symptomatic UIA* & $34(4.0)$ & $4(14)$ & $30(3.6)$ & 0.006 \\
\hline Preop mRS score $\geq 1^{*}$ & $77(9.0)$ & $13(45)$ & $64(7.8)$ & $<0.0001$ \\
\hline Multiple aneurysms & $167(20)$ & $3(10)$ & $164(20)$ & 0.20 \\
\hline $\mathrm{PTI}^{*}$ & $53(6.2)$ & $11(38)$ & $42(5.1)$ & $<0.0001$ \\
\hline Previously treated UIA* & $34(4.0)$ & $8(28)$ & $26(3.2)$ & $<0.0001$ \\
\hline Bypass surgery* & $109(13)$ & $20(69)$ & 89 (11) & $<0.0001$ \\
\hline Intraop rupture & $10(1.2)$ & $1(3.4)$ & $9(1.1)$ & 0.25 \\
\hline Postop rupture* & $4(0.5)$ & $3(10)$ & $1(0.1)$ & $<0.0001$ \\
\hline
\end{tabular}

\section{» CONTINUED FROM PREVIOUS COLUMN}

\section{TABLE 2. Analysis of factors related to poor outcome at 12} months

$\mathrm{ACA}=$ anterior cerebral artery; $\mathrm{ACh} \mathrm{A}=$ anterior choroidal artery; $\mathrm{ACoA}=$ anterior communicating artery; ICA = internal carotid artery; $\mathrm{MCA}=$ middle cerebral artery; NS = not significant; $\mathrm{PCA}=$ posterior cerebral artery; $\mathrm{PCOA}=$ posterior communicating artery; PICA = posterior inferior cerebellar artery; $\mathrm{pt}$ = patient; $\mathrm{PTI}=$ perforator territory infarction; $\mathrm{VA}=$ vertebral artery.

Data expressed as number of cases (\%), unless otherwise indicated.

* Variables significantly related to poor outcome in univariate analysis.

$\dagger$ Variables significantly related to poor outcome by adjusted residual analysis.

were selected. First, variables were compared between patients with and without poor outcome at 12 months by univariate analysis. A multivariate logistic regression analysis was performed using variables that were significantly associated with poor outcome in the univariate analysis. Second, we compared the clinical and radiological characteristics of patients with and without postoperative $\mathrm{SAH}$ by means of the log-rank test and performed multivariate analysis by means of a Cox proportional hazards model using variables that were significantly associated with the postoperative SAH on the log-rank test. Differences were considered significant at $\mathrm{p}<0.05$.

\section{Results}

The median age of the 702 patients included in this study was 64 years (IQR 56-71 years). A total of 852 aneurysms were treated (each considered a single surgical case), with 167 (20\%) of these lesions occurring in patients with multiple UIAs. Six hundred seventy-one $(79 \%)$ of the 852 aneurysms were in women. The mean follow-up period was 731 days (SD 380 days) and no patient was lost to follow-up. The distribution of mRS scores is shown in Table 1 . Among 77 cases in which the patients' postoperative $\mathrm{mRS}$ scores were greater than 1 , the causes of $\mathrm{mRS}$ score decrease were other comorbidities (in 34 cases [4.0\%]),

TABLE 3. Multivariate analysis of factors related to poor outcome at 12 months

\begin{tabular}{lccc}
\hline \multicolumn{1}{c}{ Variable } & OR & $95 \% \mathrm{Cl}$ & $\mathrm{p} \mathrm{Value}$ \\
\hline Age $>65$ yrs & 2.3 & $0.73-7.3$ & 0.15 \\
\hline Male sex & 2.6 & $0.84-8.3$ & 0.096 \\
\hline Thrombosed UIA & 2.9 & $0.50-18$ & 0.23 \\
\hline Nonclippable UIA & 1.5 & $0.32-6.7$ & 0.63 \\
\hline Large or giant UIA & 3.8 & $0.71-20$ & 0.12 \\
\hline BA aneurysm & 11 & $3.4-34$ & $<0.0001$ \\
\hline Symptomatic UIA & 0.22 & $0.018-2.7$ & 0.24 \\
\hline Preop mRS score $>1$ & 1.3 & $0.19-8.2$ & 0.80 \\
\hline PTI* & 4.0 & $1.2-14$ & 0.029 \\
\hline Previously treated UIA & 4.2 & $0.81-21$ & 0.088 \\
\hline Bypass surgery & 4.5 & $0.98-21$ & 0.053 \\
\hline Postop rupture & 13 & $0.049-3502$ & 0.37 \\
\hline BA
\end{tabular}

$\mathrm{BA}=$ basilar artery.

* Variables significantly related to poor outcome. 
TABLE 4. Summary of cases of postoperative SAH

\begin{tabular}{|c|c|c|c|c|c|c|c|c|}
\hline Case & $\begin{array}{l}\text { Age (yrs) } \\
\text { Sex }\end{array}$ & $\begin{array}{l}\text { Aneurysm } \\
\text { Location }\end{array}$ & $\begin{array}{l}\text { Aneurysm } \\
\text { Size }(\mathrm{mm})\end{array}$ & $\begin{array}{l}\text { Previous } \\
\text { Treatment }\end{array}$ & Treatment & Bypass & $\begin{array}{l}\text { Time Btwn Op } \\
\& \text { SAH (days) }\end{array}$ & $\begin{array}{l}\text { mRS } \\
\text { Score }\end{array}$ \\
\hline 1 & $70, M$ & BA trunk & 30.6 & None & BA occlusion & $V_{3}-S V G-P_{2 a}$, STA-SCA, STA-AICA & 32 & 6 \\
\hline 2 & $70, \mathrm{~F}$ & ACoA & 4.1 & None & Neck clipping & $\mathrm{A}_{3}-\mathrm{A}_{3}$ & 11 & 0 \\
\hline 3 & $66, \mathrm{~F}$ & BA-SCA & 42.2 & None & BA occlusion & STA-SCA, STA-PCA & 29 & 6 \\
\hline 4 & $70, \mathrm{~F}$ & BA top & 9.6 & Coil & Partial clipping & & 23 & 4 \\
\hline
\end{tabular}

$\mathrm{AICA}=$ anterior inferior cerebellar artery; $\mathrm{A}_{3}=\mathrm{A}_{3}$ portion of anterior cerebral artery; $\mathrm{P}_{2 \mathrm{a}}=\mathrm{P}_{2 \mathrm{a}}$ portion of posterior cerebral artery; SCA = superior cerebellar artery; STA

= superficial temporal artery; SVG $=$ saphenous vein graft; $V_{3}=V_{3}$ portion of vertebral artery.

symptomatic UIA (in 34 cases [4.0\%]), and morbidities due to previous UIA treatment (in 12 cases [1.4\%]). Bypass surgery was performed in 109 cases (13\%). Among these cases, low-flow bypasses were performed in $55(6.5 \%)$ and combinations of low-flow and high-flow bypasses in 59 cases $(6.9 \%)$.

A summary of clinical and radiological characteristics is shown in Table 2 . Age $\geq 65$ years, male sex, unclippable aneurysm morphology, large or giant aneurysm size, basilar top and basilar trunk artery aneurysms, thrombosed aneurysms, nonsaccular aneurysms, symptomatic UIAs, preoperative $\mathrm{mRS}$ score $\geq 1$, perforator territory infarction on postoperative diffusion-weighted MRI, treatment with bypass surgery, and postoperative SAH were significantly related to poor outcome at 12 months after surgery (29 cases [3.4\%]) by univariate analysis (Table 2). In multivariate analysis, perforator territory infarction and basilar artery location were significantly related to poor 12-month outcome (Table 3 ). Other variables showed no significant association with poor 12-month outcome. Median aneurysm size in UIAs with perforator territory infarction was $8.0 \mathrm{~mm}$ (IQR $3.6-13 \mathrm{~mm}$ ) and it was significantly larger than those without perforator territory infarction $(4.6 \mathrm{~mm}$ [IQR 3.4-6.5 mm]), p < 0.0001).

One patient died due to anticoagulant-related intracerebral hemorrhage (international normalization ratio $>10$ ) 10 months after aneurysm treatment. The overall followup time for the 852 UIAs was 1708 aneurysm-years. During follow-up, postoperative SAH was observed in 4 cases, yielding an overall annual rupture rate of $0.23 \%$ (95\% CI $0.12 \%-0.59 \%$ ) (Table 4). The log-rank test revealed that basilar artery location, giant aneurysm size, and unclippable status were significantly related to postoperative SAH (Table 5). Even in multivariate analysis, basilar artery location and unclippable status remained significantly related to postoperative SAH (Table 5). Other variables showed no significant association with postoperative SAH. In regard to clippable UIAs, during the follow-up period (1552 aneurysm-years) postoperative SAH was observed in 1 case (Table 4). Therefore, the annual rupture rate for clippable UIAs was $0.066 \%$ (95\% CI 0.017\%-0.37\%).

The distribution of $\mathrm{mRS}$ scores by case is shown for the 767 clippable UIAs in Table 1. Among clinical and radiological characteristics, large or giant aneurysm size, perforator territory infarction, and previously treated aneurysm were significantly related to poor outcome at 12 months $(n=11,1.4 \%)$. After multivariate analysis, these 3 variables remained significant (Table 6). Other variables showed no significant association with poor 12-month outcome for clippable UIAs.

Details of 2 of the 4 cases in which postoperative $\mathrm{SAH}$ was observed are given below. For details of the other 2 cases, please refer to the recently published article by Matsukawa et al. on the treatment of unruptured basilar artery aneurysms. $^{24}$

\section{Illustrative Cases of Postoperative SAH Case 1}

This 70-year-old man with a thrombosed giant basilar trunk aneurysm was referred to our hospital due to worsening symptoms of brainstem compression (Fig. 1A). He underwent saphenous vein $\mathrm{V}_{3}$ to $\mathrm{P}_{2 \mathrm{a}}$ bypass (placement of a saphenous vein graft between the $V_{3}$ segment of the vertebral artery and the $\mathrm{P}_{2 \mathrm{a}}$ segment of the posterior cerebral artery), superficial temporal artery-to-superior cerebellar artery bypass, and superficial temporal artery-to-anterior inferior cerebellar artery bypass with basilar artery occlusion (Fig. 1B). Although he had no neurological worsening, he suddenly developed a subarachnoid hemorrhage due to rupture of the treated basilar trunk aneurysm and died 32 days after the operation (Fig. 1C).

TABLE 5. Multivariate analyses using the Cox proportional hazards model for postoperative SAH

\begin{tabular}{|c|c|c|c|c|c|c|c|c|}
\hline \multirow[b]{2}{*}{ Variable } & \multicolumn{2}{|c|}{ Rupture } & \multicolumn{3}{|c|}{ Univariate Analysis } & \multicolumn{3}{|c|}{ Multivariate Analysis } \\
\hline & Present $(n=4)$ & Absent $(n=848)$ & $\mathrm{HR}$ & $95 \% \mathrm{Cl}$ & p Value & $\mathrm{HR}$ & $95 \% \mathrm{Cl}$ & $p$ Value \\
\hline BA aneurysm* & $3(75)$ & $62(7.3)$ & 37 & $3.8-352$ & 0.002 & 23 & $2.0-255$ & 0.0012 \\
\hline Giant & $2(50)$ & $26(3.1)$ & 30 & $4.2-212$ & 0.001 & 1.8 & $0.16-21$ & 0.63 \\
\hline Nonclippable UIA* & $3(75)$ & $81(9.6)$ & 28 & $2.9-267$ & 0.004 & 15 & $1.1-215$ & 0.046 \\
\hline
\end{tabular}


TABLE 6. Analysis of factors related to poor outcome at 12 months in patients with clippable UIAs

\begin{tabular}{|c|c|c|c|c|c|c|c|c|c|}
\hline \multirow[b]{2}{*}{ Variable } & \multirow{2}{*}{$\begin{array}{c}\text { Total } \\
(n=767)\end{array}$} & \multicolumn{2}{|c|}{ Poor Outcome } & \multicolumn{3}{|c|}{ Univariate Analysis } & \multicolumn{3}{|c|}{ Multivariate Analysis } \\
\hline & & Present $(n=11)$ & Absent $(n=756)$ & OR & $95 \% \mathrm{Cl}$ & $p$ Value & OR & $95 \% \mathrm{Cl}$ & $\mathrm{p}$ Value \\
\hline Large or giant UIA* & $28(3.7)$ & $3(27)$ & $25(3.3)$ & 11 & $2.7-44$ & 0.0010 & 8.4 & $1.9-35$ & 0.0040 \\
\hline Perforator infarction* & $39(5.1)$ & $3(27)$ & $36(4.8)$ & 7.5 & $1.9-29$ & 0.0040 & 5.4 & $1.3-23$ & 0.020 \\
\hline Previously treated ${ }^{*}$ & $20(2.6)$ & $2(18)$ & $18(2.4)$ & 9.1 & $1.8-45$ & 0.0070 & 6.7 & $1.2-36$ & 0.027 \\
\hline
\end{tabular}

Data expressed as number of cases (\%), unless otherwise indicated. Multivariate analysis was performed using variables that were significantly related to poor outcome by the univariate analysis.

* Variables significantly related to poor outcome.

\section{Case 2}

This 70-year-old woman was referred to our hospital because she hoped to be treated surgically for an unruptured anterior communicating artery aneurysm (Fig. 2A). An interhemispheric approach was performed. During observation of the aneurysm and surrounding structures, the aneurysm ruptured. The rupture point was the aneurysm neck near the right $A_{1}-A_{2}$ junction. Complete neck clipping was performed (Fig. 2B). Immediately after the operation, the patient had no neurological deficits. However, 11 days postoperatively, she developed a subarachnoid hemorrhage due to rupture of the treated aneurysm (Fig. 2C). 3D CT angiography revealed no aneurysm recurrence. The rupture point was the aneurysm neck near the right $A_{1}-A_{2}$ junction. Aneurysm trapping was performed between the right $A_{1}$, anterior communicating artery, and right $A_{2}$ in combination with an $\mathrm{A}_{3}-\mathrm{A}_{3}$ side-to-side anastomosis. The patient was discharged to home without neurological deficits (mRS score of 0 ).

\section{Discussion}

The present study showed the annual rupture rate after surgical treatment and risk factors of postoperative SAH in patients with UIAs. Despite the inclusion of complex and larger UIAs in this case series, there was a low incidence of surgical complications and a high proportion of good outcomes.

The annual rupture risk has been reported to be between $0.5 \%$ and $1.4 \%$ in the most recent relatively large $(>100$ patients) cohort studies for natural history of UIAs, despite substantially different demographic characteristics, risk factor rates, and UIA characteristics in the groups studied
(Table 7). ${ }^{12,15,18,30,31,36,44}$ Larger aneurysm size, younger age, female sex, current smoking, history of SAH, daughter sac, and specific locations (anterior communicating artery, vertebrobasilar circulation, and internal carotid-posterior communicating artery junction) were significant predictive risk factors for rupture of UIAs. ${ }^{12,15,18,30,31,36,44}$ Because so-called preventive treatments of UIAs have become common, these current natural course studies are biased. ${ }^{17}$ Therefore, it has been speculated that the true natural course of UIAs will never be described, ${ }^{33}$ and the annual rupture rates that have been reported might be relative underestimates.

As stated by Tsutsumi et al., "An optimistic assumption is that appropriate surgical treatment of aneurysms would eliminate the rupture risk or at least reduce it to the level of [the] normal population." 38 To date, a few studies have investigated posttreatment rupture (Table 7). ${ }^{3,11,19,21,26,28}$ In the present study, posttreatment rupture was observed in 4 cases ( $0.57 \%$ of all UIAs) and annual rupture rates after surgical treatments were $0.23 \%$ overall and $0.065 \%$ for clippable UIAs. The risk factors were basilar artery aneurysm location and unclippable UIA status. Although these results should not be simply compared with the annual risks of SAH in the natural course studies, annual rupture rates in the present study were lower than those observed in the natural history. In spite of inclusion of symptomatic and complex UIAs, an excellent outcome (mRS score of 0 or 1) was achieved in 816 cases $(95.7 \%)$ overall and in 748 cases $(98 \%)$ of clippable UIAs. Our surgical results were comparable or superior to those reported in previous studies. Due to technical advances, microsurgery for UIAs can be performed more safely than previously and may be jus-
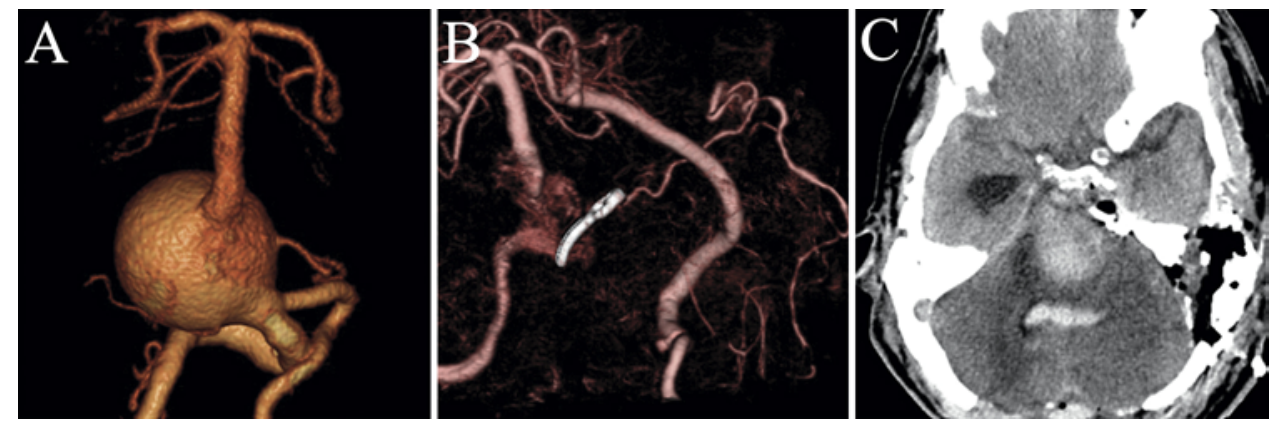

FIG. 1. Case 1. Preoperative 3D CT angiography showed a giant basilar trunk aneurysm (A). Postoperative 3D CT angiography showed that the basilar artery was occluded by a clip and bypasses were patent (B). Subarachnoid hemorrhage was observed 32 days after the operation $(\mathbf{C})$. Figure is available in color online only. 

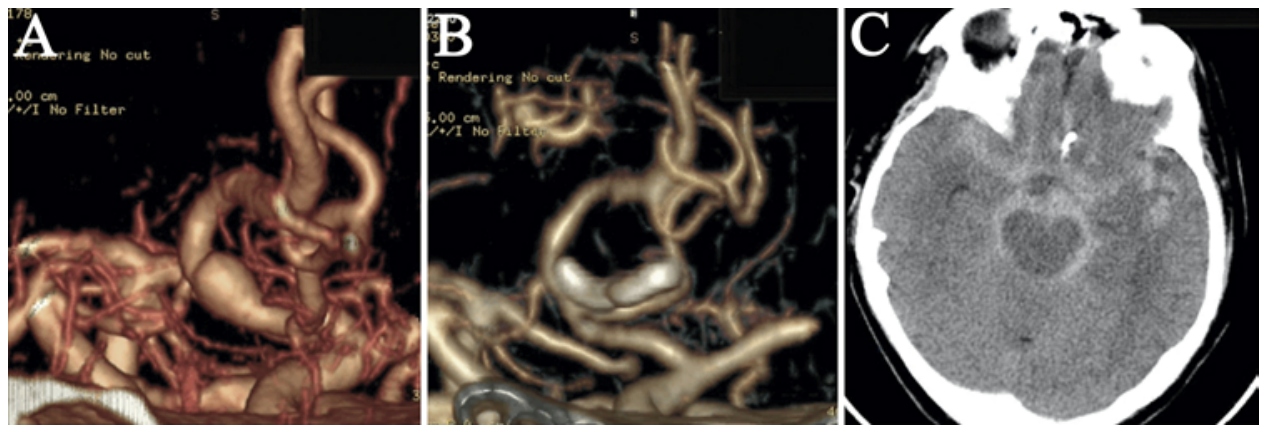

FIG. 2. Case 2. Postoperative 3D CT angiography showed the anterior communicating artery aneurysm (A). Although complete neck clipping was confirmed (B), subarachnoid hemorrhage was observed 11 days after the operation (C). Figure is available in color online only.

tified. However, the perforator territory infarction rate was still high (6.2\%) in our study and was associated with poor outcome at 12 months. This is one of the problems that need to be solved in the surgical management of UIAs.

The PHASES score provides an estimate of the absolute risk of aneurysm rupture based on 6 factors (population, hypertension, age, size of aneurysm, earlier SAH from another aneurysm, site of aneurysm).$^{10}$ This score has also been found useful for identifying aneurysms with a high relative risk of growth. ${ }^{2}$ In addition to the PHASES score, older age, female sex, smoking history, hypertension, nonsaccular UIAs, multiplicity of UIAs, larger initial aneurysm size, and specific locations (cavernous internal carotid and basilar artery) have been thought to be associated with an increased risk of aneurysm growth. 1,4,6,23,29,32,41 Korja et al. ${ }^{18}$ indicated that because even small UIAs can rupture, treatment decisions should not be based solely on aneurysm size. As stated above, the size of UIAs with perforator territory infarction was larger than those without perforator territory infarction. Therefore, we suggest that curative microsurgery for small UIAs, especially basilar artery aneurysms, with risk factors for aneurysm growth might be one of the treatment options considered after discussion of the natural history of UIAs and the risk of morbidity and mortality associated with surgical treatment.

Although our results should not be simply compared with the annual risks of SAH from studies of the natural course of aneurysms, they do show that modern microsurgery for UIAs can safely reduce the incidence of SAH. Our study provides additional evidence to support clip ligation as a durable treatment modality for the management of UIAs.

TABLE 7. Natural history and posttreatment SAH in UIAs

\begin{tabular}{|c|c|c|c|c|c|c|}
\hline Authors \& Year & No. of Pts \& UIAs & Follow-Up & $\begin{array}{c}\mathrm{SAH} \\
\text { (no. of cases) }\end{array}$ & $\begin{array}{c}\text { Size } \\
\text { in } \mathrm{mm}^{*}\end{array}$ & $\begin{array}{c}\text { Annual } \\
\text { Rupture Rate } †\end{array}$ & Others \\
\hline \multicolumn{7}{|l|}{ Natural history } \\
\hline Murayama et al., 2016 & 1556 pts w/ 1960 UIAs & 7388 aneurysm-yrs & 56 & $3.4 \pm 2.2$ & $0.76(0.58-0.98)$ & \\
\hline Korja et al., 2014 & $118 \mathrm{pts}$ & 2782 aneurysm-yrs & 34 & $4(2-25)$ & 1.2 & \\
\hline Juvela et al., 2013 & 142 pts w/ 181 UIAs & 3064 pt-yrs & 34 & $5.1 \pm 3.7$ & 1.1 & \\
\hline Morita et al., 2012 & 6697 UIAs & 11,660 aneurysm-yrs & 111 & $5.7 \pm 3.6$ & $0.95(0.79-1.15)$ & \\
\hline Sonobe et al., 2010 & 374 pts w/ 448 UIAs & 1307 pt-yrs & 7 & $3.3 \pm 0.9$ & 0.54 & Small UIAs \\
\hline Ishibashi et al., 2009 & 419 pts w/ 529 UIAs & 1312 aneurysm-yrs & 19 & NA & 1.4 & \\
\hline Wiebers et al., 2003 & 1692 pts w/ 2686 UIAs & 6544 pt-yrs & 51 & $7.4 \pm 6.9$ & 0.78 & \\
\hline \multicolumn{7}{|l|}{ Posttreatment rupture } \\
\hline \multicolumn{7}{|l|}{ Direct surgery } \\
\hline Hokari et al., 2013 & $144 \mathrm{pts}$ & 1137 pt-yrs & 2 & NA & 0.18 & Clipping \\
\hline Matsumoto et al., 2003 & 110 pts w/132 UIAs & 449 aneurysm-yrs & 1 & $7.0 \pm 5.5$ & 0.22 & Clipping, AC UIAs \\
\hline Tsutsumi et al., 1998 & $115 \mathrm{pts}$ & 1012 pt-yrs & 4 & NA & 0.39 & Direct surgery \\
\hline \multicolumn{7}{|l|}{ Endovascular treatment } \\
\hline Lopes et al., 2014 & 410 pts w/ 464 UIAs & 951 aneurysm-yrs & 2 & NA & 0.21 & Stent \& coil \\
\hline Brinjikji et al., 2013 & 1451 pts w/ 1654 UIAs & NA & 66 & NA & NA & FD \\
\hline Kulcsár et al., 2011 & NA & NA & 13 & $22 \pm 6$ & NA & FD \\
\hline
\end{tabular}

$\mathrm{AC}=$ anterior circulation; $\mathrm{FD}=$ flow diverter $\mathrm{NA}=$ not available; $\mathrm{Pts}=$ patients.

* Data expressed as a mean $\pm \mathrm{SD}$ or median (IQR).

$\dagger$ Values in parentheses are $95 \%$ Cls. 


\section{Limitations}

Some limitations of this study should be mentioned. Our study had a retrospective design, with inherent limitations that may lead to ascertainment bias, and did not address the influence of endovascular therapy, which should be considered in any decision-making process involving the treatment of UIAss. ${ }^{14,20}$ Nevertheless, reliable comparison of the risks of endovascular and surgical treatment of aneurysms is difficult because of differences between individual patients and lesions. A treatment indication paradigm in which neurosurgeons decide about the preferred treatment for individual cases on a case-by-case basis inherently causes selection bias. Although our study reconfirmed the efficacy of microsurgery for UIAs in terms of postoperative SAH, the risk of de novo aneurysm formation was significant after 9 years, and in a previous study of the long-term results of clip ligation of ruptured and unruptured aneurysms, some patients who developed de novo aneurysms appeared to have SAH due to bleeding from these new lesions. ${ }^{37}$ In light of the fatality rate of $\mathrm{SAH}$, follow-up investigation may be indicated 9-10 years after surgery even for patients with completely clipped aneurysms, for whom the accumulated risk of aneurysm recurrence might exceed $10 \% .{ }^{37}$ The follow-up period of the present study was therefore relatively short. As noted by Tsutsumi et al., "surgery does not change the underlying vascular condition that contributed to aneurysm formation," ${ }^{38}$ thus longer follow-up is needed. As noted above, the results of the present study should be further clarified in a study design employing an independent cohort to lead to more concrete and revealing findings.

\section{Conclusions}

The present study showed that basilar artery location and unclippable morphologies were related to postoperative $\mathrm{SAH}$, although surgical treatments were durable and could be performed safely in patients with UIAs.

\section{References}

1. Backes D, Rinkel GJ, Laban KG, Algra A, Vergouwen MD: Patient- and aneurysm-specific risk factors for intracranial aneurysm growth: a systematic review and meta-analysis. Stroke 47:951-957, 2016

2. Backes D, Vergouwen MD, Tiel Groenestege AT, Bor AS, Velthuis BK, Greving JP, et al: PHASES score for prediction of intracranial aneurysm growth. Stroke 46:1221-1226, 2015

3. Brinjikji W, Murad MH, Lanzino G, Cloft HJ, Kallmes DF: Endovascular treatment of intracranial aneurysms with flow diverters: a meta-analysis. Stroke 44:442-447, 2013

4. Brinjikji W, Zhu YQ, Lanzino G, Cloft HJ, Murad MH, Wang $\mathrm{Z}$, et al: Risk factors for growth of intracranial aneurysms: a systematic review and meta-analysis. AJNR Am J Neuroradiol 37:615-620, 2016

5. Brown MA, Parish J, Guandique CF, Payner TD, Horner $\mathrm{T}$, Leipzig T, et al: A long-term study of durability and risk factors for aneurysm recurrence after microsurgical clip ligation. J Neurosurg 126:819-824, 2017

6. Burns JD, Huston J III, Layton KF, Piepgras DG, Brown RD Jr: Intracranial aneurysm enlargement on serial magnetic resonance angiography: frequency and risk factors. Stroke 40:406-411, 2009

7. Chalouhi N, Bovenzi CD, Thakkar V, Dressler J, Jabbour P,
Starke RM, et al: Long-term catheter angiography after aneurysm coil therapy: results of 209 patients and predictors of delayed recurrence and retreatment. J Neurosurg 121:11021106, 2014

8. David CA, Vishteh AG, Spetzler RF, Lemole M, Lawton MT, Partovi S: Late angiographic follow-up review of surgically treated aneurysms. J Neurosurg 91:396-401, 1999

9. Ebina K, Suzuki M, Andoh A, Saitoh K, Iwabuchi T: Recurrence of cerebral aneurysm after initial neck clipping. Neurosurgery 11:764-768, 1982

10. Greving JP, Wermer MJ, Brown RD Jr, Morita A, Juvela S, Yonekura M, et al: Development of the PHASES score for prediction of risk of rupture of intracranial aneurysms: a pooled analysis of six prospective cohort studies. Lancet Neurol 13:59-66, 2014

11. Hokari M, Kuroda S, Nakayama N, Houkin K, Ishikawa T, Kamiyama H: Long-term prognosis in patients with clipped unruptured cerebral aneurysms-increased cerebrovascular events in patients with surgically treated unruptured aneurysms. Neurosurg Rev 36:567-572, 2013

12. Ishibashi T, Murayama Y, Urashima M, Saguchi T, Ebara M, Arakawa H, et al: Unruptured intracranial aneurysms: incidence of rupture and risk factors. Stroke 40:313-316, 2009

13. Ishikawa T, Nakayama N, Moroi J, Kobayashi N, Kawai H, Muto T, et al: Concept of ideal closure line for clipping of middle cerebral artery aneurysms - technical note. Neurol Med Chir (Tokyo) 49:273-278, 2009

14. Johnston SC, Higashida RT, Barrow DL, Caplan LR, Dion JE, Hademenos G, et al: Recommendations for the endovascular treatment of intracranial aneurysms: a statement for healthcare professionals from the Committee on Cerebrovascular Imaging of the American Heart Association Council on Cardiovascular Radiology. Stroke 33:2536-2544, 2002

15. Juvela S, Poussa K, Lehto H, Porras M: Natural history of unruptured intracranial aneurysms: a long-term follow-up study. Stroke 44:2414-2421, 2013

16. Juvela S, Poussa K, Porras M: Factors affecting formation and growth of intracranial aneurysms: a long-term follow-up study. Stroke 32:485-491, 2001

17. Korja M, Juvela S, Hernesniemi J: Unruptured cerebral aneurysms in a Japanese cohort. N Engl J Med 367:1268-1269, 2012 (Letter)

18. Korja M, Lehto H, Juvela S: Lifelong rupture risk of intracranial aneurysms depends on risk factors: a prospective Finnish cohort study. Stroke 45:1958-1963, 2014

19. Kulcsár Z, Houdart E, Bonafé A, Parker G, Millar J, Goddard AJ, et al: Intra-aneurysmal thrombosis as a possible cause of delayed aneurysm rupture after flow-diversion treatment. AJNR Am J Neuroradiol 32:20-25, 2011

20. Lanterna LA, Tredici G, Dimitrov BD, Biroli F: Treatment of unruptured cerebral aneurysms by embolization with Guglielmi detachable coils: case-fatality, morbidity, and effectiveness in preventing bleeding - a systematic review of the literature. Neurosurgery 55:767-778, 2004

21. Lopes DK, Johnson AK, Kellogg RG, Heiferman DM, Keigher KM: Long-term radiographic results of stent-assisted embolization of cerebral aneurysms. Neurosurgery 74:286291, 2014

22. Mason AM, Cawley CM, Barrow DL: Surgical management of intracranial aneurysms in the endovascular era: review article. J Korean Neurosurg Soc 45:133-142, 2009

23. Matsubara S, Hadeishi H, Suzuki A, Yasui N, Nishimura $\mathrm{H}$ : Incidence and risk factors for the growth of unruptured cerebral aneurysms: observation using serial computerized tomography angiography. J Neurosurg 101:908-914, 2004

24. Matsukawa H, Kamiyam H, Miyazaki T, Kinoshita Y, Tsuboi T, Noda K: Surgical treatment of unruptured distal basilar artery aneurysm: durability and risk factors for neurological worsening. Acta Neurochir (Wien) 159:1633-1642, 2017 
25. Matsukawa H, Kamiyama H, Tsuboi T, Noda K, Ota N, Miyata $\mathrm{S}$, et al: Is age a risk factor for poor outcome of surgical treatment of unruptured intracranial aneurysms? World Neurosurg 94:222-228, 2016

26. Matsukawa H, Tanikawa R, Kamiyama H, Tsuboi T, Noda K, Ota N, et al: Risk factors for low-flow related ischemic complications and neurologic worsening in patients with complex internal carotid artery aneurysm treated by EC-IC high-flow bypass. World Neurosurg 85:49-55, 2016

27. Matsukawa H, Tanikawa R, Kamiyama H, Tsuboi T, Noda $\mathrm{K}$, Ota N, et al: Risk factors for neurological worsening and symptomatic watershed infarction in internal carotid artery aneurysm treated by extracranial-intracranial bypass using radial artery graft. J Neurosurg 125:239-246, 2016

28. Matsumoto K, Akagi K, Abekura M, Nakajima Y, Yoshiminie $\mathrm{T}$ : Investigation of the surgically treated and untreated unruptured cerebral aneurysms of the anterior circulation. Surg Neurol 60:516-523, 2003

29. Miyazawa N, Akiyama I, Yamagata Z: Risk factors for growth of unruptured intracranial aneurysms: follow-up study by serial $0.5-\mathrm{T}$ magnetic resonance angiography. Neurosurgery 58:1047-1053, 2006

30. Morita A, Kirino T, Hashi K, Aoki N, Fukuhara S, Hashimoto $\mathrm{N}$, et al: The natural course of unruptured cerebral aneurysms in a Japanese cohort. N Engl J Med 366:2474-2482, 2012

31. Murayama Y, Takao H, Ishibashi T, Saguchi T, Ebara M, Yuki I, et al: Risk analysis of unruptured intracranial aneurysms: prospective 10-year cohort study. Stroke 47:365-371, 2016

32. Phan TG, Huston J III, Brown RD Jr, Wiebers DO, Piepgras DG: Intracranial saccular aneurysm enlargement determined using serial magnetic resonance angiography. J Neurosurg 97:1023-1028, 2002

33. Rasmussen PA, Mayberg MR: Defining the natural history of unruptured aneurysms. Stroke 35:232-233, 2004

34. Raymond J, Guilbert F, Weill A, Georganos SA, Juravsky L, Lambert A, et al: Long-term angiographic recurrences after selective endovascular treatment of aneurysms with detachable coils. Stroke 34:1398-1403, 2003

35. Rinkel GJ: Natural history, epidemiology and screening of unruptured intracranial aneurysms. Rev Neurol (Paris) 164:781-786, 2008

36. Sonobe M, Yamazaki T, Yonekura M, Kikuchi H: Small unruptured intracranial aneurysm verification study: SUAVe study, Japan. Stroke 41:1969-1977, 2010

37. Tsutsumi K, Ueki K, Morita A, Usui M, Kirino T: Risk of aneurysm recurrence in patients with clipped cerebral aneurysms: results of long-term follow-up angiography. Stroke 32:1191-1194, 2001

38. Tsutumi K, Ueki K, Usui M, Kwak S, Kirini T: Risk of sub- arachnoid hemorrhage after surgical treatment of unruptured cerebral aneurysms. Stroke 30:1181-1184, 1999

39. Tsutsumi K, Ueki K, Usui M, Kwak S, Kirino T: Risk of recurrent subarachnoid hemorrhage after complete obliteration of cerebral aneurysms. Stroke 29:2511-2513, 1998

40. van Swieten JC, Koudstaal PJ, Visser MC, Schouten HJ, van Gijn J: Interobserver agreement for the assessment of handicap in stroke patients. Stroke 19:604-607, 1988

41. Villablanca JP, Duckwiler GR, Jahan R, Tateshima S, Martin NA, Frazee J, et al: Natural history of asymptomatic unruptured cerebral aneurysms evaluated at CT angiography: growth and rupture incidence and correlation with epidemiologic risk factors. Radiology 269:258-265, 2013

42. Vlak MH, Algra A, Brandenburg R, Rinkel GJ: Prevalence of unruptured intracranial aneurysms, with emphasis on sex, age, comorbidity, country, and time period: a systematic review and meta-analysis. Lancet Neurol 10:626-636, 2011

43. von Elm E, Altman DG, Egger M, Pocock SJ, Gøtzsche PC, Vandenbroucke JP: The Strengthening the Reporting of Observational Studies in Epidemiology (STROBE) statement: guidelines for reporting observational studies. Lancet 370:1453-1457, 2007

44. Wiebers DO, Whisnant JP, Huston J III, Meissner I, Brown RD Jr, Piepgras DG, et al: Unruptured intracranial aneurysms: natural history, clinical outcome, and risks of surgical and endovascular treatment. Lancet 362:103-110, 2003

\section{Disclosures}

The authors report no conflict of interest concerning the materials or methods used in this study or the findings specified in this paper.

\section{Author Contributions}

Conception and design: Tanikawa, Matsukawa, Kamiyama. Acquisition of data: Matsukawa, Tsuboi, Noda, Ota, Miyata, Miyazaki, Kinoshita, Saito. Analysis and interpretation of data: Matsukawa. Drafting the article: Matsukawa. Critically revising the article: Tanikawa. Reviewed submitted version of manuscript: Tanikawa, Matsukawa. Statistical analysis: Matsukawa, Takahashi. Administrative/technical/material support: Tanikawa, Kamiyama, Tsuboi, Noda, Ota, Miyata, Miyazaki, Kinoshita, Saito, Takeda, Tokuda. Study supervision: Tanikawa, Kamiyama, Tsuboi, Noda, Ota, Miyata, Takeda, Tokuda.

\section{Correspondence}

Rokuya Tanikawa, Department of Neurosurgery, Stroke Center, Teishinkai Hospital, 3-1, Higashi 1, Kita 33, Higashi-ku, Sapporo, Hokkaido, Japan, 065-0033. email: taniroku@gmail.com. 